\title{
Investigating a Physiotherapy Clinical Simulation Assessment Tool Using The Delphi Approach
}

Anne Jones

James Cook University Australia, anne.jones@jcu.edu.au

Allison Mandrusiak

University of Queensland, a.mandrusiak@uq.edu.au

Belinda Judd

The University of Sydney, Australia, belinda.judd@sydney.edu.au

Christopher Gordon

The University of Sydney, Australia, christopher.gordon@sydney.edu.au

Jennifer Alison

The University of Sydney, jennifer.alison@sydney.edu.au

Follow this and additional works at: https://nsuworks.nova.edu/ijahsp

Part of the Physiotherapy Commons

\section{Recommended Citation}

Jones A, Mandrusiak A, Judd B, Gordon C, Alison J. Investigating a Physiotherapy Clinical Simulation Assessment Tool Using The Delphi Approach. The Internet Journal of Allied Health Sciences and Practice. 2017 Jan 01;15(3), Article 3.

This Manuscript is brought to you for free and open access by the College of Health Care Sciences at NSUWorks. It has been accepted for inclusion in Internet Journal of Allied Health Sciences and Practice by an authorized editor of NSUWorks. For more information, please contact nsuworks@nova.edu. 


\title{
Investigating a Physiotherapy Clinical Simulation Assessment Tool Using The Delphi Approach
}

\begin{abstract}
ABSTRACT

Purpose: Simulation in physiotherapy education is increasing, but a standardised assessment tool for student performance in simulation has not been developed. The Assessment of Physiotherapy Practice (APP) is a validated tool for student performance in the clinical workplace, and has been used recently for simulation despite its relevance for this context being unknown. The purpose of the study was to gain consensus about which APP items should be included in a tool to assess physiotherapy students' performance in simulation. The relevance of items was considered for both single patient encounters, and longitudinal (multiple) encounters. Methods: An online Delphi approach used a custom designed survey. A purposive sample of physiotherapists with simulation experience was recruited via email. Two rounds were undertaken with consensus being reached when at least $80 \%$ of the panel agreed on inclusion or exclusion of an item. Results: Twenty participants responded in the first round and fourteen in the second (70\% retention). For longitudinal simulations, all APP items reached consensus in the first round. For single patient simulation encounters, consensus was not reached in the first round for the following items: commitment to learning (61\%), teamwork (76\%) and discharge planning (72\%). In the second round, consensus for 'teamwork' remained the only item below eighty percent agreement (78.6\%). Conclusions: The APP was deemed to be an appropriate measure for longitudinal clinical simulations, and with the exclusion of teamwork, for a single patient simulation encounter.
\end{abstract}

\section{Author Bio(s)}

Dr Jones, BSc (Physiotherapy), M Physiotherapy, PhD, is a senior lecturer at James Cook University who has extensive practical and research experience in the field of simulation and acute care/ cardiorespiratory Physiotherapy.

Dr Mandrusiak, B Physiotherapy, PhD, is a lecturer at The University of Queensland and has experience in simulated learning and clinical education in physiotherapy.

Ms Judd, BAppSc (Physiotherapy), MEd, is an Associate Lecturer in Work Integrated Learning, University of Sydney, and also a PhD candidate comparing the simulated and clinical practice environment in Physiotherapy.

Dr GordonBN, MExSc, PhD, is Senior Lecturer of Acute Care/Critical Care Nursing, University of Sydney whose research focuses on the psychophysiological stress-learning paradigm and translation of simulation-based education to clinical practice.

Dr Alison, DipPhysiotherapy, MSc, PhD is Professor of Respiratory Physiotherapy, University of Sydney and Conjoint Professor of Allied Health, Sydney Local Health District and was instrumental in establishing the Clinical Simulation Unit in the Faculty of Health Sciences, University of Sydney. 


\title{
TIAHSP \\ The Internet Joưnal of Allied Health Sciences and Practice \\ Dedicated to allied health professional practice and education \\ Vol. 15 No. 3 ISSN 1540-580X \\ Investigating a Physiotherapy Clinical Simulation Assessment Tool Using The Delphi Approach
}

\author{
Anne Jones, BSc (Physiotherapy), M Physiotherapy, $\mathrm{PhD}^{1}$ \\ Allison Mandrusiak, BPhysiotherapy, $\mathrm{PhD}^{2}$ \\ Belinda Judd, BAppSc (Physiotherapy), MEd ${ }^{3}$ \\ Christopher Gordon, BN, MExSc, Phd ${ }^{3}$ \\ Jennifer Alison, DipPhysiotherapy, Msc, $\mathrm{PhD}^{3}$ \\ 1. James Cook University \\ 2. University of Queensland \\ 3. University of Sydney
}

Australia

\begin{abstract}
Purpose: Simulation in physiotherapy education is increasing, but a standardised assessment tool for student performance in simulation has not been developed. The Assessment of Physiotherapy Practice (APP) is a validated tool for student performance in the clinical workplace, and has been used recently for simulation despite its relevance for this context being unknown. The purpose of the study was to gain consensus about which APP items should be included in a tool to assess physiotherapy students' performance in simulation. The relevance of items was considered for both single patient encounters, and longitudinal (multiple) encounters. Methods: An online Delphi approach used a custom designed survey. A purposive sample of physiotherapists with simulation experience was recruited via email. Two rounds were undertaken with consensus being reached when at least $80 \%$ of the panel agreed on inclusion or exclusion of an item. Results: Twenty participants responded in the first round and fourteen in the second (70\% retention). For longitudinal simulations, all APP items reached consensus in the first round. For single patient simulation encounters, consensus was not reached in the first round for the following items: commitment to learning $(61 \%)$, teamwork ( $76 \%$ ) and discharge planning $(72 \%)$. In the second round, consensus for 'teamwork' remained the only item below eighty percent agreement (78.6\%). Conclusions: The APP was deemed to be an appropriate measure for longitudinal clinical simulations, and with the exclusion of teamwork, for a single patient simulation encounter.
\end{abstract}

\section{INTRODUCTION}

The use of simulated clinical environments to enhance learning for physiotherapy students has grown rapidly over the past decade as evidenced by the increase in research in this area. ${ }^{1-4}$ Simulation in physiotherapy can range from the use of part-task trainers through to full patient simulators (mannequins) and trained actors (standardised patients), ${ }^{4}$ and can involve a single encounter, or multiple encounters over a period of days or weeks. The surge in uptake of simulation in physiotherapy has been supported by the known benefits to student learning such as the ability to practice repeatedly in a safe environment whilst receiving feedback and without the time constraints that can occur in clinical practice. 3,4

Two large multi-centre randomised controlled studies carried out in Australia with physiotherapy students across several different curricula areas reported that $25 \%$ replacement of traditional clinical placement time with simulation training using standardised patients resulted in similar attainment of clinical competencies compared to students who received traditional clinical placements only. ${ }^{1,2}$ These studies support uptake of simulation in physiotherapy curricula as a substitute for some clinical hours, driven in part by the increasing demand for clinical placements. As simulation is increasing in physiotherapy education, there is a need to establish instruments that are appropriate for measuring student performance in this setting. 
In the studies by Blackstock et al. and Watson et al., student competencies were measured using the standard clinical competency tool, i.e. the Assessment of Physiotherapy Practice (APP) that is used in Australia and New Zealand. 1,2,5 Further, a more recent study involving 16 Australian Universities has also used the APP for assessing student performance in physiotherapy simulations. ${ }^{6}$ However, the APP was designed to evaluate student competencies in the clinical workplace and was not designed for simulation settings. ${ }^{5}$ Currently there are no physiotherapy-specific tools designed to measure the outcomes of simulation-based clinical education.

In our study, the selection of the APP as an outcome measures was a logical starting point because of its extensive use in physiotherapy clinical practice settings, as well as in recent research in simulation. The APP has 20 items, each of which have a number of corresponding performance indicators that the clinical educator uses to determine a score from 0-4 for each item. Whilst the reliability and validity of the APP has been established for physiotherapy students in the clinical workplace, its appropriateness for measuring performance in simulation is now being considered. ${ }^{5} \mathrm{~A}$ recent Rasch analysis demonstrated construct validity of the APP for longitudinal simulation, but for single simulation encounters, many items were considered notapplicable by clinical educators. ${ }^{7}$ The appropriateness of the APP for both single encounter and longitudinal simulations should be investigated. The aim of this study was to obtain consensus amongst physiotherapists and educators about which items of the APP should be included in a tool to assess physiotherapy students' clinical competence in simulated clinical environments.

\section{METHOD}

\section{Research Design}

Utilizing the APP as a starting point, physiotherapy educators with experience in simulation were invited to take part in a Delphi study to identify which items should be included in an outcome measure for physiotherapy student performance in clinical simulation. A Delphi approach was used as it allows for accessing expert opinion, and the online approach allows for unbiased opinions to be provided without intimidation and without the need for face-to-face meetings. 8,9

\section{Panel selection and composition}

Purposeful sampling was used to target physiotherapy educators known to be involved in clinical simulation. Potential participants were contacted via email with information regarding the study and a link to the SurveyMonkey $®$ site. Further suitable participants were invited by the initial target group, who were asked to forward the study information to appropriate colleagues with experience in simulation. Sample sizes in the literature for Delphi panels have ranged from 10 to $1685 .{ }^{9}$ The study was approved by the James Cook University Human Ethics Committee (H5569) and informed consent was implied when participants completed and submitted the survey.

\section{Consensus}

Two Delphi rounds were undertaken two months apart to allow participants time to react to questions, reflect on their answers, and alter their views if required.9,10 Further rounds were planned if issues were raised from round two that warranted investigation. A priori, consensus was considered to be achieved when at least $80 \%$ of the panel agreed on inclusion or exclusion of an item. ${ }^{8}$

\section{Procedure}

As the APP is a validated instrument to measure physiotherapy students' competence in the clinical setting, the Delphi survey was developed based on the items of the APP which can be seen in Table 1. Each item on the APP has a number of performance indicators. ${ }^{5}$ Demographic data was collected to identify the roles and experience of participants with relation to physiotherapy education, clinical simulation and their use of the APP. The survey was divided into a section regarding simulation delivered as a single 'patient' (actor/ mannequin) encounter and a section regarding multiple 'patient' (actor/ mannequin) encounters called here 'longitudinal' clinical simulation. Longitudinal clinical simulation could include multiple encounters with the same or different patient over a period of time. Participants were invited to rate which APP items should be included in an outcome measure for a single patient simulation encounter and then the same questions were asked related to longitudinal simulation. The Delphi survey was piloted first with three physiotherapists who had experience in both single and longitudinal patient simulations. Minor changes were made to the wording of the survey to aid understanding. 
Table 1: Items of the Assessment of Physiotherapy Practice ${ }^{5}$

1. Student demonstrates an understanding of patient/client rights and consent

2. Student demonstrates commitment to learning

3. Student demonstrates ethical, legal \& culturally sensitive practice

4. Student demonstrates teamwork

5. Student communicates effectively and appropriately - Verbal/non-verbal

6. Student demonstrates clear and accurate documentation

7. Student conducts an appropriate patient/client interview

8. Student selects and measures relevant health indicators and outcomes

9. Student performs appropriate physical assessment procedures

10. Student appropriately interprets assessment findings

11. Student identifies and prioritises patient's/client's problems

12. Student sets realistic short and long term goals with the patient/client

13. Student selects appropriate intervention in collaboration with patient/client

14. Student performs interventions appropriately

15. Student is an effective educator

16. Student monitors the effect of intervention

17. Student progresses intervention appropriately

18. Student undertakes discharge planning

19. Student applies evidence based practice in patient care

20. Student identifies adverse events/near misses and minimises risk associated with assessment and interventions

\section{RESULTS}

Twenty participants responded to the first round of the Delphi study, with 14/20 of these also responding in the second round (70\% retention). All participants had over five years' experience as a physiotherapist with 10/20 (50\%) having over 20 years' experience (Table 2). There was a range of physiotherapy fields of practice amongst participants, as well as a range of years of experience in simulation and in clinical education (Table 2).

Table 2: Demographic data for $\mathrm{n}=\mathbf{2 0}$ respondents. Not all respondents answered every question

\begin{tabular}{|l|l|l|}
\hline \multicolumn{1}{|c|}{ Years as a physiotherapist } & Frequency & \multicolumn{1}{c|}{ \% of respondents } \\
\hline $0-5$ & 0 & 0 \\
\hline $6-10$ & 2 & 10 \\
\hline $11-15$ & 6 & 30 \\
\hline $16-20$ & 2 & 10 \\
\hline$\geq 20$ & 10 & 50 \\
\hline Years of Simulation experience & & \\
\hline 0 & 1 & 5 \\
\hline $0-2$ & 13 & 65 \\
\hline $3-5$ & 1 & 5 \\
\hline $6-8$ & 4 & 20 \\
\hline$\geq 9$ & 1 & 5 \\
\hline Roles as an educator & & \\
\hline Clinical Educator & 1 & 5 \\
\hline Lecturer & 1 & 5 \\
\hline Simulation Facilitator & 4 & 20 \\
\hline Clinical educator \& Lecturer & 8 & 40 \\
\hline Clinical educator \& Simulation facilitator & 2 & 10 \\
\hline Clinical educator, Lecturer, \& Simulation facilitator & 3 & 15 \\
\hline Area of Expertise & & \\
\hline Cardiorespiratory & 10 & 50 \\
\hline Musculoskeletal & 4 & 20 \\
\hline Neurology & 4 & 20 \\
\hline Orthopaedics & 1 & 5 \\
\hline
\end{tabular}


Participants were involved in a variety of simulation modes and ranges of physiotherapy practice areas (Table 3). Most simulation sessions had multiple learning aims with the most frequent being for students to practice assessment and/or treatment 18/20 (90\% of respondents), communication 18/20 (90\%), clinical reasoning $17 / 20(85 \%)$, and risk management $14 / 20(70 \%)$ [Table 4]. Thirteen participants (65\%) had used the APP as an outcome measure for clinical simulation, with other examples of outcome measures being self-made check lists 10/20 (50\%), global ratings of performance $4 / 20(20 \%)$, or none at all (15\%) (Table 4).

Table 3: Experience of participants in simulation types and areas of practice.

\begin{tabular}{|l|l|l|}
\hline Simulation Format & Frequency & \% of respondents \\
\hline $\begin{array}{l}\text { Longitudinal (multiple encounter) } \\
\text { clinical simulation }\end{array}$ & 15 & 75 \\
\hline $\begin{array}{l}\text { Skills sessions mainly using part task } \\
\text { trainers }\end{array}$ & 10 & 50 \\
\hline Single patient encounter simulation & 9 & 45 \\
\hline $\begin{array}{l}\text { Simulation for an exam eg Objective } \\
\text { Structured Clinical Exam }\end{array}$ & 8 & 40 \\
\hline Workshops, two to three day courses & 1 & 5 \\
\hline Simulation Area of Practice & & \\
\hline Cardiorespiratory & 10 & 50 \\
\hline Neurological & 7 & 35 \\
\hline General rehabilitation & 6 & 30 \\
\hline Musculoskeletal & 4 & 20 \\
\hline Paediatric acute care & 4 & 20 \\
\hline Orthopaedic & 2 & 1 \\
\hline
\end{tabular}

Table 4: Intended learning outcomes and outcomes measures used for simulation experiences in which participants had been involved.

\begin{tabular}{|l|l|l|}
\hline & Frequency & \% of respondents \\
\hline Intended learning outcomes & & \\
\hline Assessment and/or treatment of a patient & 18 & 90 \\
\hline Communication & 18 & 90 \\
\hline Clinical reasoning & 17 & 85 \\
\hline Task/ skill training eg suctioning & 15 & 75 \\
\hline Risk management/safety & 14 & 70 \\
\hline Team work & 12 & 60 \\
\hline Assessment of a student eg OSCE & 8 & 40 \\
\hline Outcome measures & & \\
\hline Assessment of Physiotherapy Practice & 13 & 65 \\
\hline Satisfaction with simulation questionnaires & 12 & 60 \\
\hline Self-made performance checklist & 10 & 50 \\
\hline Student confidence questionnaires & 10 & 50 \\
\hline Global rating for performance & 4 & 20 \\
\hline Other & 4 & 20 \\
\hline None & 3 & 15 \\
\hline
\end{tabular}

\section{Round 1}

Regarding a single patient simulation encounter, in the initial round, $25 \%$ of respondents believed that it was not suitable to use the APP as an outcome measure, whilst $35 \%$ were unsure. Three participants (15\%) stated in the open comments section that the APP may not be suitable for a 'snapshot' of performance as occurs in a single patient simulation encounter as it was developed to assess student performance across time. Consensus was not achieved in round one for inclusion of the following items in a tool for a single patient simulation encounter: Item 2 (demonstrates a commitment to learning), Item 4 (demonstrates teamwork), and Item 18 (undertakes discharge planning), where $61 \%, 76 \%$, and $72 \%$ of participants, respectively, agreed that these items should be included. 
For longitudinal (multiple) clinical simulations, consensus was reached in the first round for all items of the APP to be included in a measure of student performance.

\section{Round 2}

Regarding a single patient simulation encounter, in the second round, consensus was reached amongst the 14 participants for Item 2 (demonstrates a commitment to learning) and Item 18 (undertakes discharge planning) but Item 4 (demonstrates teamwork) remained below the level of consensus at $78.6 \%$. All other items remained at $>80 \%$ agreement.

\section{DISCUSSION}

This study gained consensus about APP items that are appropriate for assessment of student performance in physiotherapy clinical simulations. For longitudinal clinical simulation encounters, all 20 APP items were deemed appropriate for assessment of performance after the first round. For a single patient simulation encounter, all items except 'demonstrates teamwork' (Item 4) were deemed appropriate after the second round. This study confirmed support amongst physiotherapy educators for the use of the APP as a suitable tool for assessment of student performance in simulated clinical settings.

Longitudinal simulations in physiotherapy focus on management of patient/s across time, similar to clinical education in the real world environment. We found that all participants agreed that all the items of the APP were appropriate for inclusion in an outcome measure for this simulation context. These findings concur with the recent study by Judd et al. which established construct validity of all APP items for longitudinal simulation. ${ }^{7}$ It is recognised that members of the panel may have been involved in the recent Australia-wide projects in which the APP was used as the outcome measure: two large multicentre trials 1,2 or the project to embed simulation into physiotherapy clinical training. ${ }^{6}$

There were mixed perceptions amongst our panel about the appropriateness of some APP items for a single patient simulation encounter. This aligns with Judd et al. in which many items were deemed to be not-applicable by clinical educators. ${ }^{7}$ Item 2 (demonstrates a commitment to learning) did not initially reach consensus for a single patient simulation encounter. The performance indicators for this item include "uses clinic time responsibly" and "takes responsibility for learning and seeks opportunities to meet learning needs." ${ }^{11}$ Other indicators of performance covered by this item include "responds in a positive manner to questions, suggestions \&/or constructive feedback," "reviews \& prepares appropriate material before \& during placement," "develops \& implements a plan of action in response to feedback," and "seeks information/assistance as required" (p. 77). ${ }^{11}$ These indicators lend to a single patient encounter and may be why despite in the first round seven out of 18 participants who answered this question chose to exclude this item, by the second round after reflection all 14 chose to include this item. It is acknowledged that some of the participants in round one who excluded this item did not respond in round two.

The other item that initially did not reach consensus for a single patient encounter session but then did so in the second round was item 18 (undertakes discharge planning). The performance indicators for this item have a focus on continuing care that may not be the focus of a single patient encounter. For example, "arranges appropriate follow up healthcare to meet short and long term goals" and "addresses client and carer needs for ongoing care through the coordination of appropriate services" are two of these performance indicators. ${ }^{11}$ However, other performance indicators for this item do relate to a single patient encounter such as, "begins discharge planning in collaboration with the healthcare team at the time of the initial episode of care" and "discusses discharge planning with the client" (p.80). ${ }^{11}$ These more detailed indicators may be a reason for why this item was chosen to be included in the second round. Again, it is acknowledged that some of the participants in round one who excluded this item did not respond in round two.

Opportunities to demonstrate teamwork (Item 4) may be limited in single patient encounters, which may in part explain why this item was not considered to be an appropriate performance measure. The performance indicators for this item include "contributes appropriately in team meetings" and "advocates for the patient/client when dealing with other services," which may not be captured in a snapshot of performance during a single patient encounter. ${ }^{11}$

Given the surge in uptake of simulation in physiotherapy clinical education, the establishment of reliable and valid outcome measures of student performance is paramount. Participants in our study reported using a range of outcome measures mostly self-made checklists or measures of satisfaction and confidence. Although measures of satisfaction and confidence may have limited value and self-made measures may have poor validity and reliability their use is understandable given the lack of a standardised performance measure for physiotherapy simulation and the need to gain insight into student perspectives about the learning experience. ${ }^{12,13}$ Our study has confirmed the perceived value of the APP as a measure of student performance in clinical simulation. Other international physical therapy programs that use validated assessment instruments to measure student performance in clinical practice, may consider a Delphi approach to begin determining the suitability of the tool for proposed use

(c) The Internet Journal of Allied Health Sciences and Practice, 2017 
in simulation-based assessments. This may include such tools as the Clinical Performance Instrument (CPI) which has been adopted widely throughout Canada and the United States, but to the best of our knowledge, has not been studied for its use in simulation-based assessments. ${ }^{14}$

Despite reminder emails, there was attrition of $30 \%$ of participants from round one to two. This may have biased the addition of the two APP items for a single patient simulation encounter; it is unknown if the participants who did not respond to round two may have continued to exclude these items. Further, whilst this study examined content validity of the APP for simulation using the Delphi process, further research is required to explore whether it can be used as a predictive tool for student performance in clinical practice settings.

\section{CONCLUSION}

This Delphi study used an expert panel of physiotherapists with simulation experience to help identify items of the APP that should be included in a tool to assess student performance in clinical simulations. For longitudinal clinical simulations, all items of the APP reached consensus in the first round. For a single patient simulation encounter, after two rounds, all items of the APP except Item 4 (demonstrates teamwork) reached consensus for inclusion in a tool to assess student performance during simulation. This study provides support for the perceived value of the APP as an outcome measure for longitudinal clinical simulations and, with the exclusion of teamwork, as a measure of student performance in a single patient simulation encounter.

\section{REFERENCES}

1. Watson K, Wright A, Morris N, McMeeken J, Rivett D, Blackstock F, et al. Can simulation replace part of clinical time? Two parallel randomised controlled trials. Medical Education. 2012;46:657-67. [PMID: 22646319]

2. Blackstock F, Morris N, Watson K, Jones A, Wright A, McMeeken J, et al. Simulation can contribute part of cardiorespiratory physiotherapy clinical education: two randomised trials. Simulation in Healthcare. 2013;8:32-42. [PMID: 23250189]

3. Jull G, Wright A, McMeeken J, Morris N, Rivett D, Blackstock F, et al. Health Workforce Australia National Simulated Learning project report for Physiotherapy.2010.

4. Jones A, Sheppard L. Can human patient simulators be used in physiotherapy education. The Internet Journal of Allied Health Sciences and Practice [serial on the Internet]. 2007; 5(2): Available from: http://ijahsp.nova.edu/articles/vol5num2/jones.pdf. Accessed March 21, 2017.

5. Dalton M, Davidson M, Keating J. The Assessment of Physiotherapy Practice (APP) is a valid measure of professional competence of physiotherapy students: a cross-sectional study with Rasch analysis. Journal of Physiotherapy. 2011;57:239-46. [PMID: 22093122]

6. Wright A, Moss P, Watson K, Rue S, Jull G, Mandrusiak A, et al. A profession-wide collaboration to embed role-play simulation into Australian entry level physiotherapy clinical training. Physiotherapy. 2015;101(Supplement 1):e1047.

7. Judd B, Scanlan J, Alison J, Waters D, Gordon C. The validity of a professional competence tool for physiotherapy students in simulation-based clinical education: a Rasch analysis. BMC Medical Education. 2016;16:196. [PMID: 27492325]

8. Keeney S, Hasson F, McKenna H. A critical review of the Delphi technique as a research methodology for nursing. Int J Nurs Stud. 2001;38:195-201.

9. Williams P, Webb C. The Delphi technique: a methodological discussion. J Adv Nurs. 1994;19:180-6. [PMID: 8138622]

10. $\quad$ Powell C. The Delphi technique: myths and realities. J Adv Nurs. 2003;41(4):376-82.

11. Dalton M, Keating J, Davidson M. Development of the Assessment of Physiotherapy Practice (APP): A standardised and valid approach to assessment of clinical competence in physiotherapy. In: Dalton M, Keating J, Davidson M, editors. Australian Learning and Teaching Council (ALTC) Final Report. Brisbane: Griffith University; 2009. p. 6-28.

12. Issenberg B, McGaghie W, Petrusa E, Gordon D, Scalese R. Features and uses of high-fidelity medical simulations that lead to effective learning: a BEME systematic review. Med Teach. 2005;27(1):10-28. [PMID: 16147767]

13. McGaghie W, Issenberg B, Petrusa E, Scalese R. A critical review of simulation based medical education research: 2003-2009. Med Educ. 2009;44(1):50-63. [PMID: 20078756]

14. Silberman N, Litwin B, Panzarella K, Fernadez- Fernandez A. Student clinical performance in acute care enhanced through simulation training. Journal of Acute Care Physical Therapy. 2016;7(1):25-36.

(c) The Internet Journal of Allied Health Sciences and Practice, 2017 